\section{Molecular Syndromology}

Mol Syndromol 2018;9:134-140

DOI: $10.1159 / 000488438$
Accepted: November 9, 2018

by M. Schmid

Published online: April 24, 2018

\title{
Longitudinal Follow-Up of Two Patients with Dysspondyloenchondromatosis due to Novel Heterozygous Mutations in COL2A1
}

\author{
Nilay Güneş ${ }^{a} \quad$ Gözde Yeşil $^{b}$ Kubilay Beng ${ }^{c}$ Sinan Kahraman ${ }^{d}$ Beyhan Tüysüz ${ }^{a}$ \\ aDepartment of Pediatric Genetics, Cerrahpaşa Medical School, Istanbul University, ${ }^{\mathrm{b}}$ Department of Medical \\ Genetics, Faculty of Medicine, Bezmialem Vakif University, ' Department of Orthopedics and Traumatology, Metin \\ Sabancı Baltalimanı Bone Diseases Training and Research Hospital, and d Department of Orthopedics, Istanbul \\ Florence Nightingale Hospital, Bilim University, Istanbul, Turkey
}

\section{Keywords}

COL2A1 - Dysspondyloenchondromatosis · Progressive scoliosis · Unequal limb length

\begin{abstract}
Dysspondyloenchondromatosis (DSC) is a rare form of generalized enchondromatosis and characterized by short stature with unequal limb length, multiple enchondromas in metaphyseal and diaphyseal parts of the long tubular bones, and progressive kyphoscoliosis. Although the COL2A1 gene mutation was found to be responsible for DSC, a case of DSC with no pathogenic mutation in the COL2A1 gene has also been reported, suggesting that the condition is genetically heterogeneous. Here, we report 2 novel heterozygous mutations in COL2A1 in 2 patients with DSC. They had prenatal onset short stature with unequal limb length and generalized enchondroma-like lesions in metaphyseal and diaphyseal parts of the long tubular bones, and osteopenia. The first patient was diagnosed at 3 months of age and followed for 10.5 years. Severe lumbosacral scoliosis and recurrent fractures were observed. The second patient was diagnosed at the age of 4 years. Mild deterioration in scoliosis was observed during the 3-year-long follow-up period. However, skeletal radiography of both patients showed the improve-
\end{abstract}

\section{KARGER}

(C) 2018 S. Karger AG, Basel

E-Mail karger@karger.com

www.karger.com/msy ment of enchondromatous lesions. In conclusion, we verified that the $C O L 2 A 1$ gene mutations are responsible for the DSC phenotype. We observed severe osteopenia and fractures which were not reported previously.

(C) 2018 S. Karger AG, Basel

Dysspondyloenchondromatosis (DSC) was first proposed as a distinctive entity by Freisinger et al. [1993] with the hallmark features: irregularly shaped vertebral bodies and enchondroma-like lesions in the metaphyseal and diaphyseal parts of the long tubular bones. Clinical and radiological features of DSC are multiple enchondromas extending from the metaphysis to the diaphysis of the long tubular bones, progressive kyphoscoliosis, anisospondyly, and short stature with asymmetric limb shortening [Nakane et al., 2011; Superti-Furga et al., 2012]. These spinal irregularities and unequal limbs were important to differentiate DSC from other enchondromatosis and spondyloenchondromatosis types (spondyloenchondrodysplasia and metaphyseal enchondromatosis with 2-hydroxyglutaric aciduria) [Spranger et al., 2002].

Nakane et al. [2011] identified a novel heterozygous missense mutation in COL2A1 in a patient with DSC and suggested that DSC may be related to type 2 collagenopa-

Beyhan Tüysüz

Istanbul Üniversitesi

Cerrahpaşa Tıp Fakültesi

Çocuk Kliniği, Cerrahpaşa, Istanbul 34098 (Turkey)

E-Mail beyhan@istanbul.edu.tr 

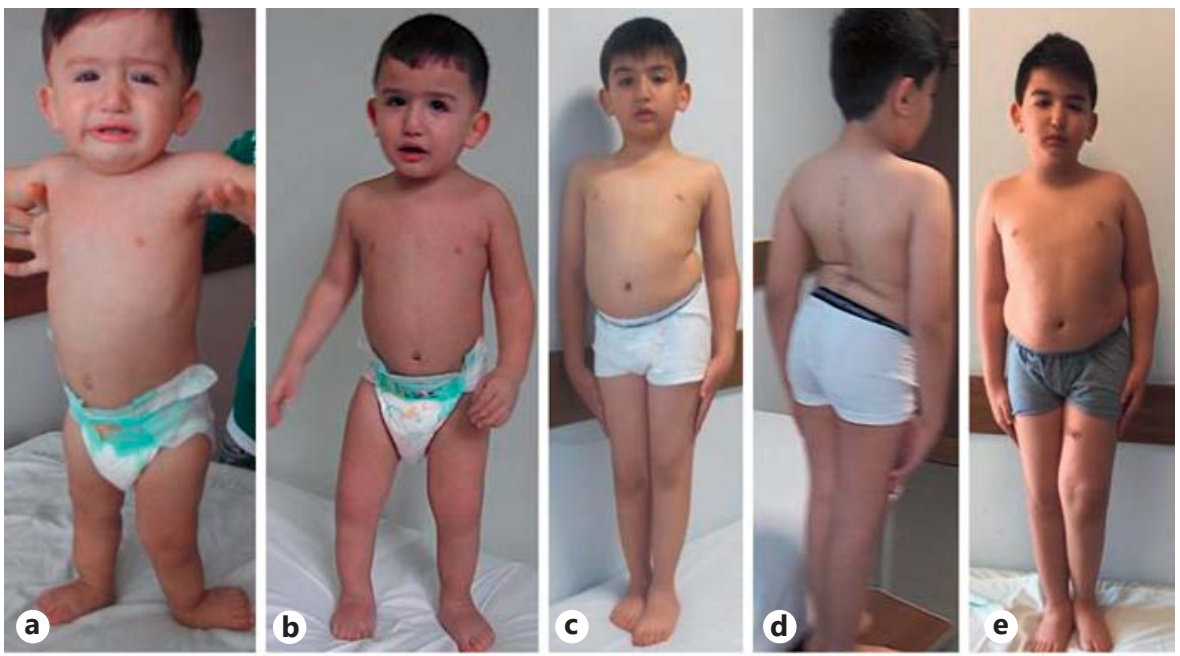

Fig. 1. Photographs of patients 1 and 2 at different ages. Patient 1 at 16 months (a), at 2.5 years $(\mathbf{b}), 8$ years $(\mathbf{c}, \mathbf{d})$ and at 10 years and 10 months (e). Note: short stature with shortening of the right lower extremity and lumbosacral scoliosis. Patient 2 at 4.5 years (f), 5.5 years $(\mathbf{g})$, and 7.5 years $(\mathbf{h}, \mathbf{i})$. Short stature, barrel-shaped thorax, thoracolumbar scoliosis, upper and lower limb length asymmetry on the right side are shown.
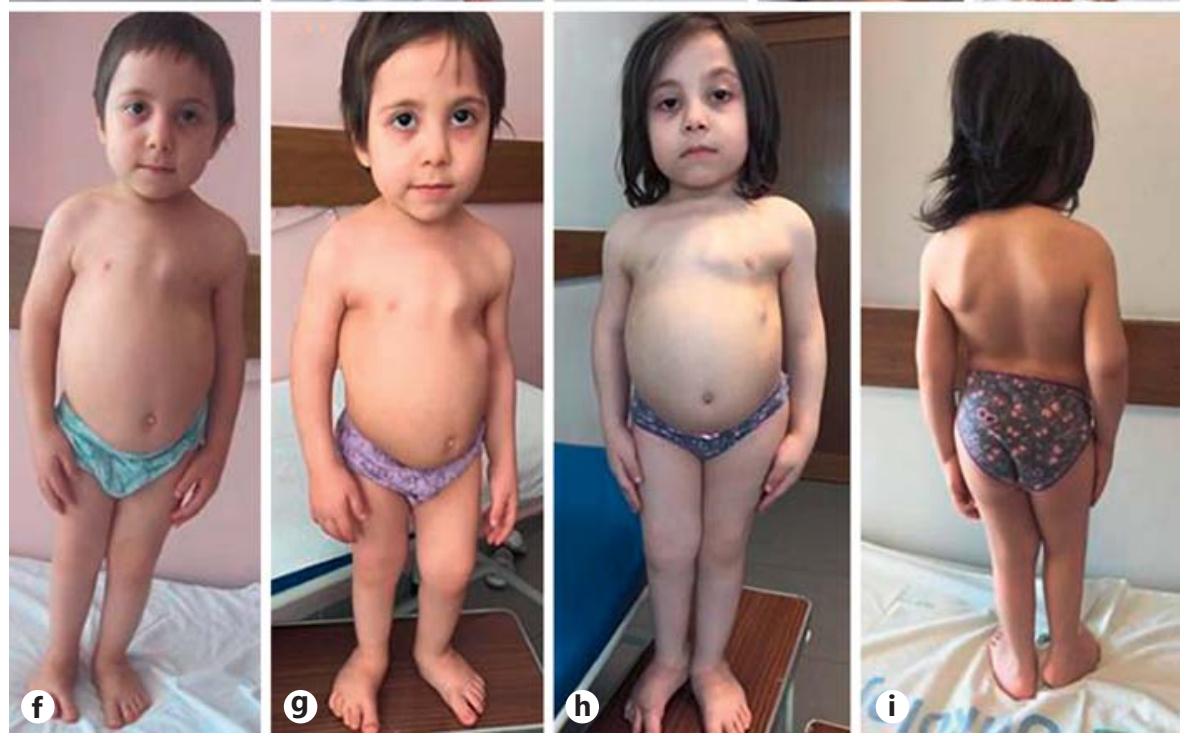

thies. However, a further case of DSC without unequal limbs was reported in which no pathogenic mutation was identified, suggesting that DSC is genetically heterogeneous [Tran Mau-Them et al., 2014]. Recently, Merrick et al. [2015] also reported a mutation in COL2A1 in a patient with DSC.

Here, we evaluate the longitudinal observation of clinical and radiological findings of 2 unrelated patients with DSC and report 2 novel mutations in the COL2A1 gene.

\section{Patients and Methods}

Patient 1

A 3-month-old baby boy was referred to our department with the prenatal diagnosis of achondroplasia. He was born at 40 weeks of gestation. His birth length was $42 \mathrm{~cm}[-4.5$ standard deviation

score (SDS)] and his weight was 2,600 g. There was no history of short stature among family members. Physical examination showed short stature with shortening of the right lower extremity and a short neck. His height was $66 \mathrm{~cm}(-3.6$ SDS) at age 1 , and 1 $\mathrm{cm}$ length difference was measured between the lower extremities (Fig. 1a). The skeletal radiography revealed enchondroma-like metaphyseal changes of proximal humeri, distal radii (Fig. 2a, d), distal femurs and proximal tibias (Fig. 2g, h), shortening of the right femur and tibia, slightly irregular shape of lumbar vertebral bodies (Fig. 3a, e), and hypoplasia of pubic bones (Fig. 3f) in the infantile period. Laboratory investigations, ophthalmic examination, hearing tests, abdominal ultrasonography, and echocardiography were normal. He was diagnosed with DSC and followed up until 10.5 years of age.

His motor milestones were delayed; however, language and mental development were appropriate to age. His leg length discrepancy was $2 \mathrm{~cm}$ at age 4 and remained the same during his follow-up (Fig. 1b-e). Lumbosacral scoliosis began at 2 years of age and showed progression (Fig. 1d). He had a fracture of the left fe-

Dysspondyloenchondromatosis

Mol Syndromol 2018;9:134-140 


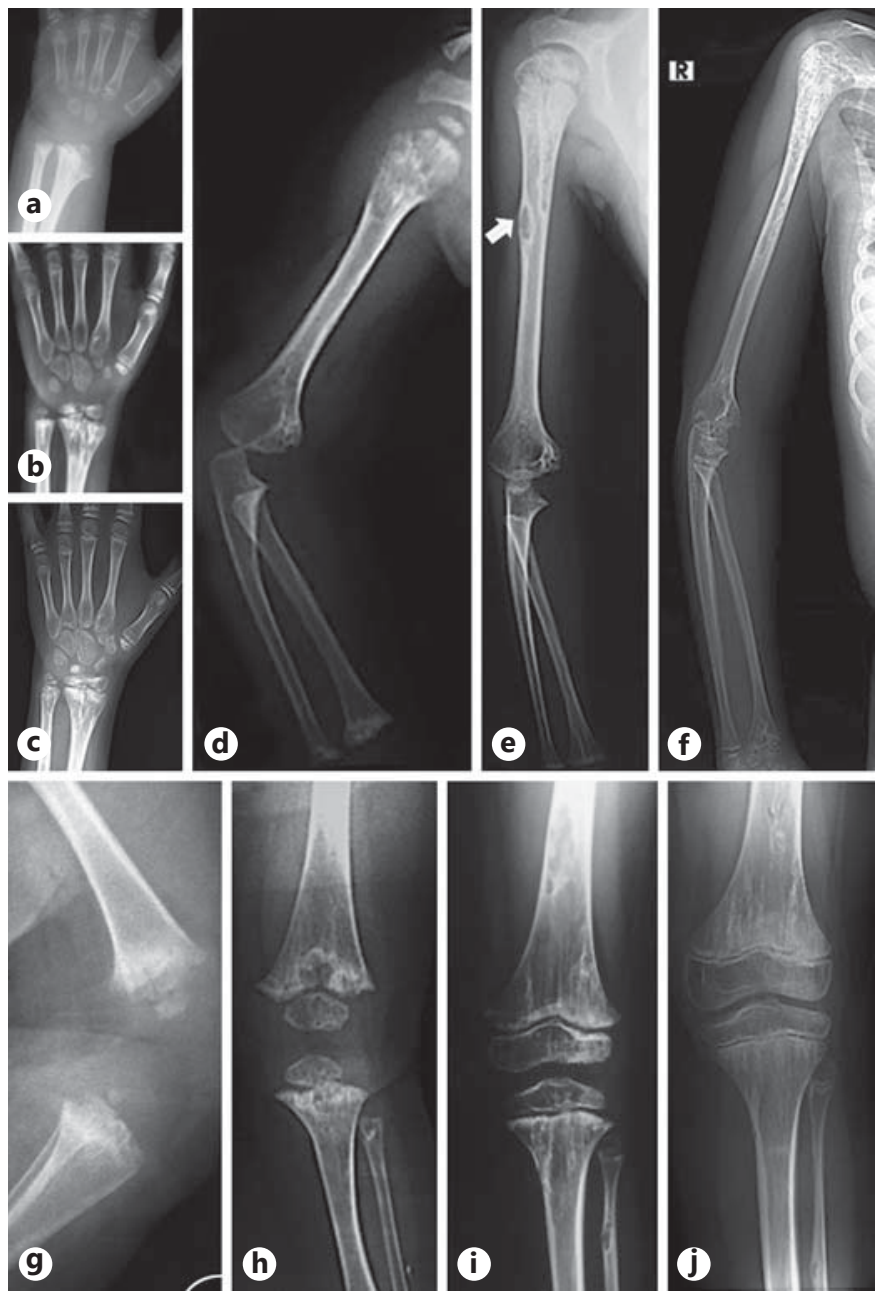

Fig. 2. Radiographs of patient 1 . Metaphyseal expansion and enchondroma-like metaphyseal changes of distal radii at 1 year (a), at 6 years (b), and at 8 years of age (c). Radiographs of the right arm at age $1(\mathbf{d})$, age $4(\mathbf{e})$, and age $9(\mathbf{f})$. The arrow shows an enchondromatous lesion on the diaphysis of the humeri (e) and its ossification during the follow-up period (f). Radiographs of the left knee at 3 months of age $(\mathbf{g})$, at age $1(\mathbf{h})$, age $4(\mathbf{i})$, and age $10(\mathbf{j})$ reveal enchondroma-like metaphyseal changes on distal femurs and proximal tibias. During the follow-up period, metaphyseal enchondromatous lesions resolved and progressed towards diaphysis.

mur at 3 years of age. Bone mineral density (BMD) assessment of the L1-L4 lumbar spine region by the Hologic Delphi technique and pediatric software analysis showed osteoporosis with a calculated $\mathrm{Z}$ score of -5.8 . Endocrine, metabolic, and nutritional disorders that are associated with reduced bone mass were excluded. Intravenous pamidronate disodium treatment was given for 6 months. He suffered 2 fracture events of the right femur at age 6 and 7. At his last visit, at the age of 10 , he was $119 \mathrm{~cm}$ (-3.39 SDS) tall and had a lower limb length difference of $2 \mathrm{~cm}$. Taking his educational achievements and our clinical assessment into consideration, his intelligence was normal.
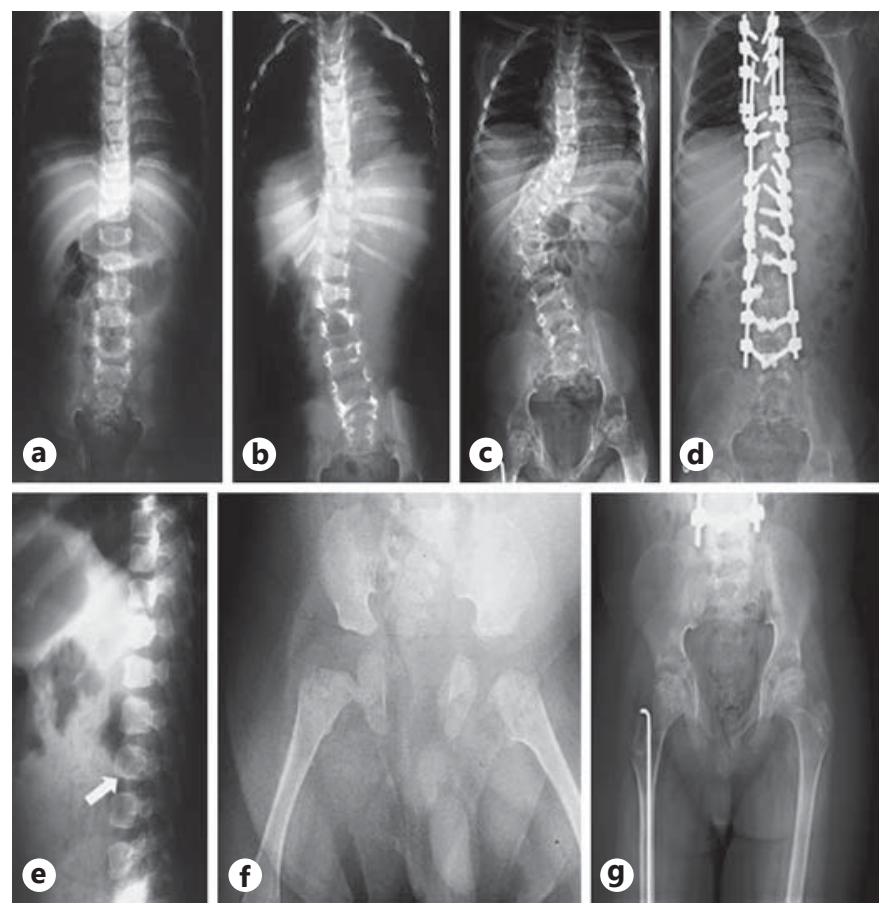

Fig. 3. Vertebral radiographs of patient 1 at age 1 (a), age 4 (b), age 9 (c), and at age $10(\mathbf{d})$. Lumbosacral scoliosis and its progression is shown in $\mathbf{b}$ and c. After surgical correction, improvement of scoliosis was observed (d). Lateral view of the patient reveals a slightly irregular shape of lumbar vertebral bodies at 1 year of age. The arrow indicates anisospondyly (e). Pelvic radiographs show hypoplasia of the pubis at 3 months of age (f) and at 10 years $(\mathbf{g})$.

During the follow-up period, the radiographs showed that metaphyseal enchondromatous lesions in the long bones resolved and progressed towards the diaphysis (Fig. $2 \mathrm{~b}, \mathrm{c}, \mathrm{e}, \mathrm{f}, \mathrm{h}-\mathrm{j}$ ); progressive scoliosis was also observed (Fig. 3b, c). Surgical correction of the spinal deformity was performed at age 10 (Fig. 3d). Spinal MRI did not show any medulla spinalis defect or narrowing of the spinal channel despite the $\mathrm{S}$-shaped scoliosis. The pubic bones also were hypoplastic (Fig. $3 g$ ) at 10 years of age.

\section{Patient 2}

A 4.5-year-old-girl was admitted due to a dislocation of the right hip. She was born uneventfully at term, and her birth length was $41 \mathrm{~cm}(-4$ SDS). At the age of 4.5 years, physical examination showed a barrel-shaped thorax, thoracolumbar scoliosis, difficulty in extension of both elbows, and upper and lower limb length asymmetry (Fig. 1f, g). The right upper limb was $1.5 \mathrm{~cm}$ and the right lower limb was $2.5 \mathrm{~cm}$ shorter than the left limbs. Lumbar hyperlordosis was observed.

The skeletal radiography revealed upper and lower limb length asymmetry, cystic radiolucency, and an irregularity on the metaphysis and diaphysis of the long tubular bones, predominantly in the distal femurs and radii as well as proximal tibias and humeri in the initial examination (Fig. 4a, c, d, g). Spinal involvement with irregular size and shape of vertebral bodies and mild thoracolum- 

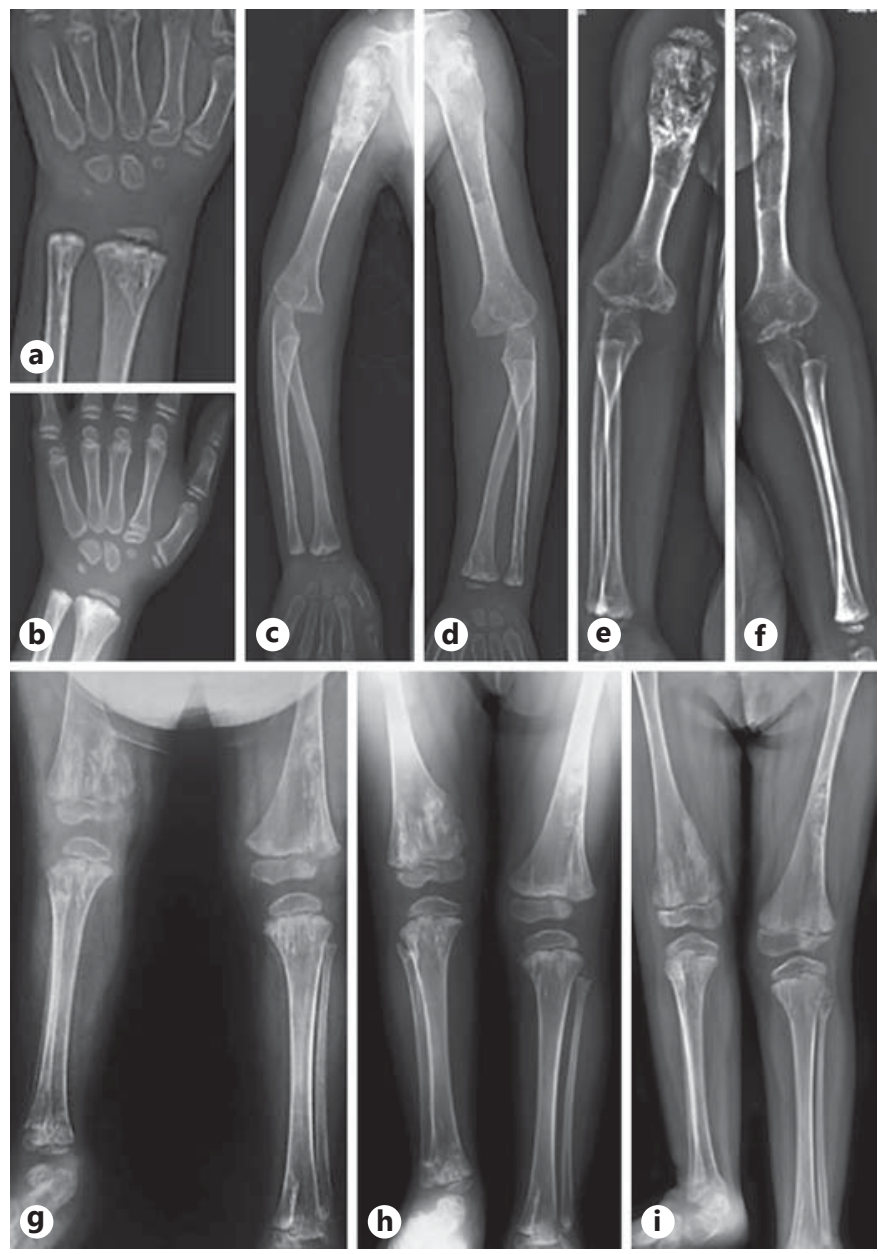

Fig. 4. Radiographs of patient 2. Metaphyseal expansion and enchondroma-like metaphyseal changes of distal radii at age 4 (a) and at 6 years of age (b). The upper extremities at age $4(\mathbf{c}, \mathbf{d})$ and $7(\mathbf{e}, \mathbf{f})$ show that the right side is shorter than the left. Enchondroma-like metaphyseal changes of proximal humeri progressed towards diaphysis with aging (e). The lower extremities at age 4 (g), 5 (h), and 7 (i) reveal shortening of right side, cystic radiolucency, and irregularity on the metaphysis and diaphysis of the long tubular bones, predominantly femora and tibias. During the follow-up period, mild regression of the metaphyseal irregularity was observed (i).

bar scoliosis were detected (Fig. 5a, b). The pelvis graphy showed hypoplasia of the pubis and absence of the right femoral neck and right femoral capital epiphysis with irregular metaphyseal ossification of the proximal right femur. The left femoral capital epiphysis was small and irregular (Fig. 5d).

Spinal MRI confirmed thoracolumbar scoliosis and irregularity of vertebral bodies, mimicking segmentation anomalies of dorsal vertebrae. The laboratory investigations, ophthalmic examination, and hearing tests were normal. Her intelligence was appropriate to her age according to our clinical assessment and her achievements at school.

Dysspondyloenchondromatosis
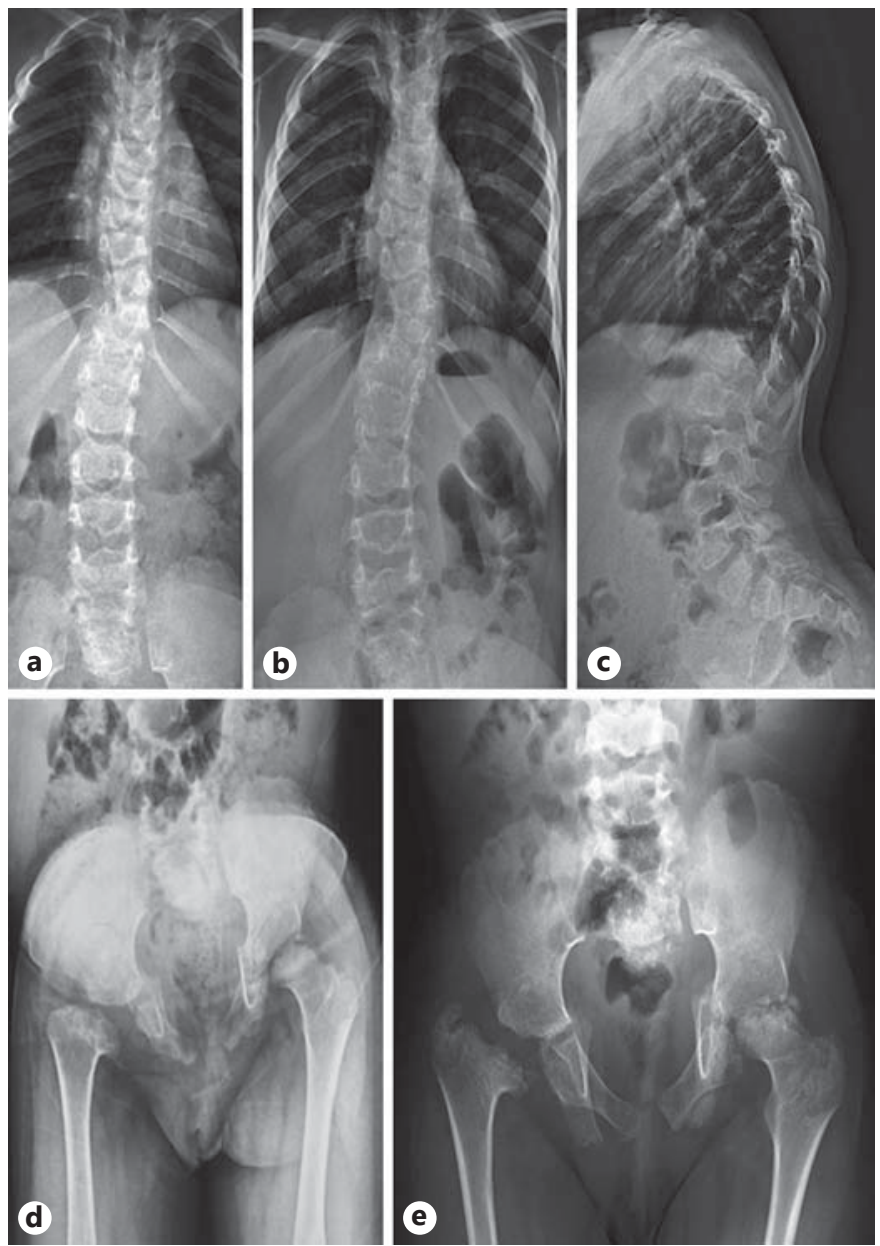

Fig. 5. Radiographs of patient 2 at the age of 5 (a) and 7 years (b, c). Spinal involvement with irregular size and shape of vertebral bodies and mild thoracolumbar scoliosis is shown. During the follow-up period, mild deterioration in scoliosis was detected. Pelvic radiographs show a hip dislocation, invisible femoral neck, and femoral capital epiphysis with irregular metaphyseal ossification of the proximal femur on the right side. The left femoral capital epiphysis was small and irregular at the age of $4(\mathbf{d})$. The right femoral epiphysis appeared as fragmented ossicles at age 7 (e). Hypoplasia of the pubic bones also is present.

At her last visit, at age 7 (Fig. 1h, i), she was $84 \mathrm{~cm}$ tall $(-7.6$ SDS). We observed $1.5 \mathrm{~cm}$ length difference between the upper limbs and $4 \mathrm{~cm}$ between the lower limbs within a 3-year follow-up.

After 3 years, her radiographs showed mild regression of the metaphyseal irregularity (Fig. 4b, e, f, h, i). Lumbar hyperlordosis and mild deterioration in scoliosis were observed on vertebral radiographs (Fig. 5b, c). The right femoral epiphysis appeared as fragmented ossicles on the pelvic X-ray at 7 years of age (Fig. 5e).

Although the initial BMD assessment of the L1-L4 lumbar spine region showed osteoporosis with a calculated $\mathrm{Z}$ score of -4.2 , she had never experienced a fracture. Endocrine, metabolic, and nutritional disorders thought to reduce the bone mass were ex-

Mol Syndromol 2018;9:134-140 
Table 1. Comparison of the clinical and radiological features of the patients in this study to those in reported patients with DSC

\begin{tabular}{|c|c|c|c|c|c|c|c|c|c|}
\hline & \multicolumn{2}{|l|}{ Present patients } & \multirow{2}{*}{$\begin{array}{l}\text { Mainzer et al., } \\
1971 \\
\text { P } 1\end{array}$} & \multirow{2}{*}{$\begin{array}{l}\text { Spranger et al., } \\
1978\end{array}$} & \multirow[t]{2}{*}{ Azouz, 1987} & \multirow{2}{*}{$\begin{array}{l}\text { Lerman-Sagie } \\
\text { et al., } 1987\end{array}$} & \multicolumn{3}{|c|}{ Freisinger et al., 1993} \\
\hline & P 1 & P 2 & & & & & P 1 & P 2 & P 3 \\
\hline Gender & M & $\mathrm{F}$ & $\mathrm{F}$ & M & M & $\mathrm{F}$ & M & M & $\mathrm{F}$ \\
\hline Birth height, $\mathrm{cm} / \mathrm{SDS}$ & $42 /-4.5$ & $41 /-4$ & NA & $40 /-3.6$ & NA & NA & $40.5 /-3.4$ & $43 /-2.5$ & $41 /-4$ \\
\hline Age at diagnosis & $3 \mathrm{mo}$ & 4 yrs & $18 \mathrm{mo}$ & 4 yrs & 3 yrs & $2 \mathrm{yrs}, 7 \mathrm{mo}$ & 3 yrs, $6 \mathrm{mo}$ & $13 \mathrm{mo}$ & $2 \mathrm{yrs}, 6 \mathrm{mo}$ \\
\hline Age & $10 \mathrm{yrs}, 6 \mathrm{mo}$ & $7 \mathrm{yrs}$ & $20 \mathrm{yrs}$ & 4 yrs & $3 \mathrm{yrs}$ & $2 \mathrm{yrs}, 7 \mathrm{mo}$ & $3 \mathrm{yrs}, 6 \mathrm{mo}$ & $13 \mathrm{mo}$ & $2 \mathrm{yrs}, 6 \mathrm{mo}$ \\
\hline Height, $\mathrm{cm} / \mathrm{SDS}$ & $\begin{array}{l}51.5 /-5^{*} \\
119 /-3.39^{* *}\end{array}$ & $\begin{array}{l}74 /-7.2^{*} \\
84 /-7.6^{* *}\end{array}$ & $117.5 /-7.6^{* *}$ & $82.5 /-6^{*}$ & $56.7 /-10.6^{*}$ & $80 /-3^{*}$ & $69 /-6^{*}$ & $63 /-5^{*}$ & $63.5 /-5.5^{*}$ \\
\hline $\begin{array}{l}\text { Asymmetric limbs } \\
\text { (detected age) }\end{array}$ & $3 \mathrm{mo}$ & $4 \mathrm{yrs}, 6 \mathrm{mo}$ & at birth & $4 \mathrm{yrs}$ & 3 yrs & $2 \mathrm{yrs}, 7 \mathrm{mo}$ & at birth & $13 \mathrm{mo}$ & $17 \mathrm{mo}$ \\
\hline Short limb & $\mathrm{R}$ leg & $\mathrm{R}$ arm, $\mathrm{R}$ leg & $\mathrm{L}$ arm, $\mathrm{R}$ leg & $\mathrm{L}$ arm, $\mathrm{L}$ leg & L leg & ND & L leg & R leg & R leg \\
\hline $\begin{array}{l}\text { Metaphyseal enchondroma- } \\
\text { like changes/expansion }\end{array}$ & $+1+$ & $+/+$ & $+/+$ & $+/+$ & $+1+$ & $+/+$ & $+1+$ & $+1+$ & $+/+$ \\
\hline Extension to the diaphysis & + & + & + & + & + & - & + & - & - \\
\hline Epiphyseal dysplasia & - & - & - & + & + & + & + & + & \\
\hline $\begin{array}{l}\text { Vertebral hypoplasia/ } \\
\text { dysplasia }\end{array}$ & general & general & general & general & thoracolumbar & thoracolumbar & thoracolumbar & general & general \\
\hline Scoliosis & $\begin{array}{l}\text { severe/ } \\
\text { lumbosacral }\end{array}$ & $\begin{array}{l}\text { moderate/ } \\
\text { thoracolumbar }\end{array}$ & $\begin{array}{l}\text { severe/ } \\
\text { thoracic }\end{array}$ & $\begin{array}{l}\text { mild/ } \\
\text { thoracolumbar }\end{array}$ & $\begin{array}{l}\text { severe/ } \\
\text { thoracolumbar }\end{array}$ & $\begin{array}{l}\text { severe/ } \\
\text { thoracolumbar }\end{array}$ & $\begin{array}{l}\text { severe/ } \\
\text { thoracolumbar }\end{array}$ & $\begin{array}{l}\text { mild/ } \\
\text { thoracic }\end{array}$ & $\begin{array}{l}\text { mild/ } \\
\text { thoracic }\end{array}$ \\
\hline Osteopenia/fractures & $+/+$ & $+1-$ & ND & ND & ND & ND & ND & ND & ND \\
\hline Atlantoaxial instability & - & - & ND & ND & ND & - & ND & ND & ND \\
\hline Pubic hypoplasia & + & + & ND & ND & + & + & + & ND & ND \\
\hline \multirow[t]{3}{*}{ COL $2 A 1$ gene mutation } & $\begin{array}{l}\text { c. } 3293 \mathrm{G}>\mathrm{A} \\
\text { (p.Gly1098Glu), } \\
\text { exon } 47\end{array}$ & $\begin{array}{l}\text { c. } 1817 \mathrm{G}>\mathrm{A} \\
\text { (p.Gly606Asp), } \\
\text { exon } 27\end{array}$ & & & & & & & \\
\hline & \multicolumn{4}{|c|}{ Kozlowski et al., 1994} & \multirow{2}{*}{$\begin{array}{l}\text { Nakane et al., } \\
2011\end{array}$} & \multirow{2}{*}{$\begin{array}{l}\text { Kenis et al., } \\
2013\end{array}$} & \multirow{2}{*}{$\begin{array}{l}\text { Tran Mau-Them } \\
\text { et al., } 2014\end{array}$} & \multirow{2}{*}{\multicolumn{2}{|c|}{$\begin{array}{l}\text { Merrick et al., } \\
2015\end{array}$}} \\
\hline & $\mathrm{P} 1$ & P 2 & P 3 & P 4 & & & & & \\
\hline Gender & M & M & $\mathrm{F}$ & M & M & M & $\mathrm{F}$ & M & \\
\hline Birth height, $\mathrm{cm} / \mathrm{SDS}$ & $46 /-1.4$ & $47.7 /-0.9$ & $39.5 /-4.8$ & $46 /-1.4$ & $41 /-3.1$ & $? /-3$ & $44 /-2.9$ & $42 / 0$ & \\
\hline Age at diagnosis & 1st day & 1 st day & 4th day & 5 weeks & 3 yrs & $5 \mathrm{yrs}$ & 5 yrs & 5 yrs & \\
\hline Age & 5 yrs & $4 \mathrm{yrs}, 6 \mathrm{mo}$ & $15 \mathrm{mo}$ & $3 \mathrm{yrs}, 9 \mathrm{mo}$ & $14 \mathrm{yrs}, 8 \mathrm{mo}$ & $5 \mathrm{yrs}$ & 5 yrs & 5 yrs & \\
\hline Height, $\mathrm{cm} / \mathrm{SDS}$ & $46 /-1.4^{*}$ & $47.7 /-0.9^{*}$ & NA & $72 /-6^{* *}$ & $103 /-9.8^{* *}$ & NA & $84.5 /-4^{*}$ & $88.5 /-6.6$ & \\
\hline $\begin{array}{r}\text { Asymmetric limbs } \\
\text { (detected age) }\end{array}$ & at birth & $2 \mathrm{yrs}, 6 \mathrm{mo}$ & at birth & 5 weeks & 3 yrs & $5 \mathrm{yrs}$ & - & 5 yrs & \\
\hline Short limb & R leg & L leg & R leg & L leg & ND & ND & - & L leg & \\
\hline $\begin{array}{c}\text { Metaphyseal enchondroma- } \\
\text { like changes/expansion }\end{array}$ & $+/+$ & $+/+$ & $+/+$ & $+/+$ & $+/+$ & $+/+$ & $+/+$ & $+/+$ & \\
\hline Extension to the diaphysis & - & - & - & + & + & ND & - & ND & \\
\hline Epiphyseal dysplasia & + & ND & ND & + & + & + & ND & + & \\
\hline $\begin{array}{l}\text { Vertebral hypoplasia/ } \\
\text { dysplasia }\end{array}$ & lumbar & lumbar & lumbar & thoracolumbar & ND & thoracolumbar & thoracic & thoracoly & umbar \\
\hline Scoliosis & $\begin{array}{l}\text { mild/ } \\
\text { lumbar }\end{array}$ & $\begin{array}{l}\text { mild/ } \\
\text { lumbar }\end{array}$ & $\begin{array}{l}\text { mild/ } \\
\text { lumbar }\end{array}$ & $\begin{array}{l}\text { severe/ } \\
\text { thoracolumbar }\end{array}$ & $\begin{array}{l}\text { severe/ } \\
\text { thoracic }\end{array}$ & $\begin{array}{l}\text { moderate/ } \\
\text { thoracic }\end{array}$ & $\begin{array}{l}\text { severe/ } \\
\text { thoracic }\end{array}$ & $\begin{array}{l}\text { moderate } \\
\text { thoracoll }\end{array}$ & imbar \\
\hline Osteopenia/fractures & ND & ND & ND & ND & ND & ND & ND & ND & \\
\hline Atlantoaxial instability & ND & ND & ND & ND & ND & ND & ND & + & \\
\hline Pubic hypoplasia & + & + & + & + & ND & + & - & + & \\
\hline COL $2 A 1$ gene mutation & & & & & $\begin{array}{l}\text { c. } 2258 \mathrm{G}>\mathrm{A} \\
\text { (p.Gly753Asp), } \\
\text { exon } 34\end{array}$ & & - & $\begin{array}{l}\text { c. } 1799 \mathrm{G} \\
\text { (p.Gly600 } \\
\text { exon } 27\end{array}$ & $\begin{array}{l}>\mathrm{A} \\
0 \text { Asp), }\end{array}$ \\
\hline
\end{tabular}

L, left; mo, months; NA, not available; ND, not described; P, patient; R, right; SDS, standard deviation score; yrs, years. * First examination. ${ }^{* *}$ Last examination.

cluded. Intravenous pamidronate disodium treatment was given for 2.5 years. On BMD measurement at age 7 , the $\mathrm{Z}$ score of BMD was -2.4 , showing mild osteoporosis.

\section{Methods}

Genomic DNA was extracted from peripheral blood samples of the patients and their parents according to standard procedures. For genomic analysis of COL2A1, 54 coding exons of the gene were amplified with long-range primers covering exons (plus exon-intron boundary regions with $50 \mathrm{bp}$ ). These long-range primers were designed according to the latest COL2A1 sequence (Gene ID: 1280, NM_001844). Amplified PCR products were prepared for next-gen- eration sequencing by Nextera XT (Illumina) protocol. The purification steps in library preparation were performed with the Agencourt AMPure XP (Beckman Coulter) kit. After library preparation, amplified and indexed PCR products were sequenced with the MiSeq ${ }^{\circledR}$ next-generation sequencing platform (Illumina). The sequencing of the sample was performed by 542.234 reads with $1,492 \times$ mean coverage. Paired-end raw sequence data that were obtained from MiSeq next-generation sequencing platform were used in analysis pipeline. Sequence data were trimmed from both $3^{\prime}$ and $5^{\prime}$ end with quality threshold Q10 via Trimmomatic. Sequences were aligned to reference sequences (COL2A1) with Burrows-Wheeler Alignment. In order to detect single nucleotide substitutions and small indels, the GATK 
Unified Genotyper was used. The detected variants were annotated with dbSNP (build 144) with ANNOVAR software. PhyloP (http:// compgen.bscb.cornell.edu/phast/help-pages/phloP.txt), SIFT (Sorting Intolerant From Tolerant; http://sift.jcvi.org), PolyPhen-2 (http:// genetics.bwh.harvard.edu/pph2), and GERP (Genomic Evolutionary Rate Profiling; SidowLab/downloads/ gerp/index.html) bioinformatics tools were used to identify the deleterious amino acid changes.

\section{Results}

Two novel heterozygous missense mutations; c.3293G >A (p.Gly1098Glu) and c.1817G >A (p.Gly606Asp) in the COL2A 1 gene, were detected in patient 1 and 2 , respectively (Table 1). These were not present in other healthy family members and are predicted to be pathogenic according to prediction databases (SIFT, PolyPhen-2). Both nucleotide changes from nonpolar amino acid glycine to polar amino acids glutamine and aspartic acid cause changes in hydrophobicity scores and also secondary structure propensities of the final protein structures.

\section{Discussion}

Nakane et al. [2011] and Merrick et al. [2015] identified novel COL $2 A 1$ mutations in 2 patients with DSC, indicating that the condition is a part of type 2 collagenopathies. However, a mutation in COL $2 A 1$ could not be detected in a patient described by Tran Mau-Them et al. [2014], and they suggested that there might be a possible genetic heterogeneity. We identified 2 novel COL $2 A 1$ gene mutations, which are predicted to be pathogenic in 2 unrelated patients with DSC. In a study of COL2A1related dysplasias, Terhal et al. [2012] showed that a glycine substitution in the triple helical domain is the most common type of pathogenic mutation in the COL $2 \mathrm{~A} 1$ gene. Missense mutations resulting in substitution of the glycine residue within triple helical domain of COL $2 \mathrm{~A} 1$ with a bulkier amino acid, such as arginine or aspartic acid, are known to be pathogenic [Merrick et al., 2015]. The reported 2 heterozygous missense mutations, c. 2258 G>A (p.Gly753Asp) and c.1799 G>A (p.Gly600Asp), by Nakane et al. [2011] and Merrick et al. [2015] lie within the triple helical domain and cause the substitution of glycine to aspartic acid, as found in our patient 2. Glycine to glutamine substitution, as found in our patient 1 , has not been reported in DSC patients before.

Superti-Furga et al. [2012] proposed a classification for enchondromatosis with molecular basis and classified DSC as a member of type 2 collagenopathies. They noted

Dysspondyloenchondromatosis that the chondromatous changes in DSC are expected to be regressive rather than progressive. We compared the clinical and radiological features of the patients in this study to those previously reported 15 patients with DSC in Table 1 [Mainzer et al., 1971; Spranger et al., 1978; Azouz, 1987; Lerman-Sagie et al., 1987; Freisinger et al., 1993; Kozlowski et al., 1994; Nakane et al., 2011; Kenis et al., 2013; Tran Mau-Them et al, 2014; Merrick et al., 2015]. All patients except for the patient of Tran MauThem et al. [2014] had asymmetric limb shortening. Merrick et al. [2015] suggested that the diagnosis of Tran Mau-Them's COL2A1 negative case might be separate from DSC, as this patient had neither pubic bone dysplasia nor hypoplasia of the lower lumbar vertebrae and also showed brachydactyly, which is unusual for COL $2 A 1$ disorders. We agree with Merrick et al. [2015] that this diagnosis might be different from DSC due to the absence of asymmetric limbs. In our patients, the localization of enchondromatous lesions on long bones was in proximal parts of humeri, femurs, and tibias as well as distal parts of ulnae, radii, and femurs. Patients of Nakane et al. [2011] and Merrick et al. [2015] showed similar localization patterns of enchondromatous lesions. The patient of Tran Mau-Them et al. [2014] had enchondromatous lesions on distal ulnae, distal radii, and vertebrae showing a different localization pattern compared to other DSC patients. As we noticed in our cases, the limb with more enchondromatous lesions may tend to be shorter.

The majority of DSC patients, including ours, had pubic hypoplasia as a feature of COL2A1 disorder [Kozlowski et al., 1994; Kenis et al., 2013; Merrick et al., 2015]. Craniofacial involvement with cleft palate, vitreoretinal degeneration, severe myopia, hearing impairment, and atlantoaxial instability are other characteristic features of type 2 collagenopathies [Kannu et al., 2012]. Cleft palate in DSC has been reported only by Kozlowski et al. [1994] and Nakane et al. [2011]. Our patients had normal ophthalmic and hearing examinations and no cleft palate. Recently, Merrick et al. [2015] found odontoid hypoplasia and mild atlantoaxial instability in their patient. Our patients had no atlantoaxial instability on cervical imaging.

Mainzer et al. [1971] reported a 20-year-long followup of 2 cases with multiple enchondromatosis. They observed typical X-ray findings of multiple enchondromatosis on long tubular bones during the first 2 years of life. After 20 years, normal ossification occurred, and only minor sclerotic densities remained. We observed that enchondromatous lesions have extended from the metaphyseal to the diaphyseal part of the long bones and had a tendency to improve during 10 years of follow-up in pa-

Mol Syndromol 2018;9:134-140 139 
tient 1 . In patient 2 , only minor improvement in metaphyseal irregularity was observed because of a shorter (3year-long) follow-up time.

The majority of DSC patients had severe scoliosis, even within the first years of life [Mainzer et al., 1971; Nakane et al., 2011]. Patient 1 reported here developed progressive scoliosis, which began at the age of 2 years. The surgical approach in DSC was concluded to be difficult because of the pathological distribution of enchondromatous lesions within the spinal structures [Kenis et al., 2013]. He underwent a vertebral operation and no complication was seen. To date, 2 DSC patients were reported having had surgical treatment to correct scoliosis [Azouz, 1987; Freisinger et al., 1993].

Osteopenia and recurrent fractures or low BMD were not reported in the patients with DSC previously. Both patients presented here demonstrated low BMD and received intravenous pamidronate treatment. We excluded endocrine, metabolic, and nutritional disorders that were possibly associated with reduced bone mass. Patient 1 had 3 fracture events and underwent an operation on the right femur. Despite very low BMD, patient 2 had no fractures. We suggest that the reduced bone mass in DSC may be a result of enchondromatous lesions.
In conclusion, we observed previously reported features such as deterioration in scoliosis and regression of the metaphyseal irregularity during long-term follow-up periods in our DSC patients presented here. Furthermore, we detected low BMD and long bone fractures, which were not reported in DSC before. We also verified that the COL2A1 gene mutation is responsible for the DSC phenotype and propose that patients with clinical and radiological features of DSC should be screened for COL $2 \mathrm{~A} 1 \mathrm{mu}$ tations to elucidate the molecular basis of the condition.

\section{Statement of Ethics}

Signed informed consent and the permission for the publication of accompanying images were obtained from the parents. The data presented in this study were retrieved from the routine clinical care facilities of Cerrahpasa School of Medicine, Istanbul, Turkey.

\section{Disclosure Statement}

The authors declare no conflicts of interest.

\section{References}

Azouz EM: Case report 418: multiple enchondromatosis (Ollier disease) with severe vertebral changes. Skeletal Radiol 16:236-239 (1987).

-Freisinger P, Finidori G, Maroteaux P: Dysspondylochondromatosis. Am J Med Genet 45: 460-464 (1993).

Kannu P, Bateman J, Savarirayan R: Clinical phenotypes associated with type II collagen mutations. J Paediatr Child Health 48:E38-43 (2012)

-Kenis V, Baindurashvili A, Melchenko E, Ganger R, Grill F, Al Kaissi A: Spinal and extraspinal deformities in a patient with dysspondyloenchondromatosis. Ger Med Sci 11:Doc06 (2013).

Kozlowski K, Brostrom K, Kennedy J, Lange H, Morris L: Dysspondyloenchondromatosis in the newborn. Report of four cases. Pediatr Radiol 24:311-315 (1994).
Lerman-Sagie T, Grunebaum M, Mimouni M: Case report 416: spondylometaphyseal chondroplasia with an unclassified mucopolysaccharide in the urine ("generalized enchondromatosis with mucopolysacchariduria"). Skeletal Radiol 16:175-178 (1987).

Mainzer F, Minagi H, Steinbach HL: The variable manifestations of multiple enchondromatosis. Radiology 99:377-388 (1971).

Merrick B, Calder A, Wakeling E: Dysspondyloenchondromatosis (DSC) associated with COL2A1 mutation: clinical and radiological overlap with spondyloepimetaphyseal dysplasia-Strudwick type (SEMD-S). Am J Med Genet A 167A:3103-3107 (2015).

- Nakane T, Tando T, Aoyagi K, Hatakeyama K, Nishimura G, et al: Dysspondyloenchondromatosis: another COL2A1-Related Skeletal Dysplasia? Mol Syndromol 2:21-26 (2011).

- Spranger J, Kemperdieck H, Bakowski H, Opitz JM: Two peculiar types of enchondromatosis. Pediatr Radiol 7:215-219 (1978).
Spranger J, Brill PW, Poznanski A: Bone Dysplasias: An Atlas of Genetic Disorders of Skeletal Development, ed 2 (Oxford University Press, New York 2002)

Superti-Furga A, Spranger J, Nishimura G: Enchondromatosis revisited: new classification with molecular basis. Am J Med Genet C Semin Med Genet 160C:154-164 (2012).

- Terhal PA, van Dommelen P, Le Merrer M, Zankl A, Simon ME, et al: Mutation-based growth charts for SEDC and other COL2A1 related dysplasias. Am J Med Genet C Semin Med Genet 160C:205-216 (2012).

Tran Mau-Them F, Boualam A, Barat-Houari M, Jeandel C, Cottalorda J, et al: Dysspondyloenchondromatosis without COL2A1 mutation: possible genetic heterogeneity. Am J Med Genet A 164A:769-773 (2014). 